\title{
Dermoscopy of Cutaneous Lymphoproliferative Disorders: Where Are We Now?
}

\author{
Vincenzo Piccolo ${ }^{a}$ Teresa Russo $^{a}$ Marina Agozzino ${ }^{a}$ Paola Vitiello $^{a}$ \\ Stefano Caccavale $^{a}$ Roberto Alfano $^{b}$ Giuseppe Argenziano ${ }^{a}$ \\ ${ }^{a}$ Dermatology Unit, University of Campania Luigi Vanvitelli, Naples, Italy; ${ }^{b}$ Department of Anesthesiology, Surgery \\ and Emergency, University of Campania Luigi Vanvitelli, Naples, Italy
}

\section{Keywords}

Dermoscopy - Lymphoma - Mycosis fungoides .

Lymphoproliferative disorders

\begin{abstract}
The prompt identification of cutaneous lymphoproliferative disorders (CLD) has always been a challenge in dermatological practice, due to the rarity of this group of diseases, the heterogeneity in clinical presentation, and plenty of variants described in the literature so far. The strict cooperation between dermatologist and pathologist is the key element for the correct diagnosis of CLD deriving from the perfect integration of clinical and histopathological features. In this complex context, dermoscopy could play an adjuvant role in the achievement of the diagnosis, as it fits itself as the third diagnostic tool in the paraphernalia of the dermatologist between the clinical and histopathological examination. This review provides the state of art of dermoscopy of CLD.
\end{abstract}

(c) 2018 S. Karger AG, Basel

\section{KARGER}

(c) 2018 S. Karger AG, Basel

E-Mail karger@karger.com

www.karger.com/drm

\section{Introduction}

Clinical diagnosis of cutaneous lymphoproliferative disorders (CLD) is one of the most difficult challenges in dermatology due to their heterogeneous and protean clinical presentation. Dermatopathologists experience the same difficulties as clinicians in the correct identification of CLD, also because of confusing terminology deriving from lack of easy univocal diagnostic features and rapidly changing classifications. The strict cooperation between dermatologist and pathologist is the key element for the correct diagnosis of CLD deriving from the perfect integration of clinical and histopathological features [1]. In this complex context, dermoscopy could play an adjuvant role in the achievement of the diagnosis, as it fits itself as the third diagnostic tool in the paraphernalia of the dermatologist between the clinical and histopathological examination.

Since 2009, when Moura et al. [2] described the dermoscopic features of lymphomatoid papulosis, interest towards dermoscopy of CLD has increasingly grown, and plenty of papers have been published on this topic [3-17]. 
Table 1. List of cutaneous lymphoproliferative disorders whose dermoscopy is known

\begin{tabular}{|c|c|}
\hline Diagnosis & Dermoscopic features \\
\hline Early-stage MF & $\begin{array}{l}\text { - } \quad \text { Fine short linear vessels } \\
\text { - } \quad \text { Orange-yellowish patchy areas }\end{array}$ \\
\hline Poikilodermatous MF & $\begin{array}{l}\text { - Polygonal white storiform streaks } \\
\text { - } \text { Dotted and hairpin vessels } \\
\text { - } \quad \text { Septa of pigmented dots } \\
\text { Red and yellowish smudges }\end{array}$ \\
\hline Pagetoid reticulosis & $\begin{array}{l}\text { - Homogeneous pink background erythema } \\
\text { - Dotted/glomerular vessels } \\
\text { - White scales }\end{array}$ \\
\hline Folliculotropic MF & $\begin{array}{l}\text { - } \text { Comedo openings } \\
\text { - } \quad \text { Perifollicular accentuation } \\
\text { - Small white structureless areas } \\
\text { - Terminal hairs }\end{array}$ \\
\hline $\begin{array}{l}\text { Primary cutaneous CD30(+) anaplastic } \\
\text { large cell lymphoma }\end{array}$ & $\begin{array}{l}\text { - } \quad \text { Pink-to-yellow structureless areas } \\
\text { - } \quad \text { Polymorphous vessels (nodular lesions) }\end{array}$ \\
\hline Lymphomatoid papulosis & $\begin{array}{l}\text { - Inflammatory phase: irregular vessels surrounded } \\
\text { by white structureless area } \\
\text { - Hyperkeratotic phase: predominance of the whitish } \\
\text { area and less evident vessels } \\
\text { - Necrotic phase: necrotic ulceration, vessels visible } \\
\text { only at the extreme periphery of each lesion }\end{array}$ \\
\hline Primary cutaneous B-cell lymphoma & $\begin{array}{l}\text { - White circles } \\
\text { - Salmon-colored background/area } \\
\text { - Scales } \\
\text { - Arborizing/serpentine vessels }\end{array}$ \\
\hline Pseudolymphoma & $\begin{array}{l}\text { - White reticular lines } \\
\text { - Pinkish background } \\
\text { - } \quad \text { Fine linear vessels }\end{array}$ \\
\hline Pseudolymphomatous folliculitis & $\begin{array}{l}\text { - Arborizing vessels } \\
\text { - Perifollicular and follicular yellowish spots } \\
\text { - Follicular red dots }\end{array}$ \\
\hline Cutaneous involvement of multiple myeloma & - "Pink cobweb"-like appearance \\
\hline
\end{tabular}

The aim of this review is to carefully collect all the published data on dermoscopy of CLD and to establish which is the most recent state of art. Table 1 summarizes all the dermoscopic features of the diseases described below.

\section{Mycosis Fungoides}

Mycosis fungoides (MF) is the most frequent primary cutaneous lymphoma of the skin and derives from $\mathrm{T}$ lymphocytes. The clinical course of MF is typically indolent, and given its slow progression, MF could show a variegate clinical presentation, ranging from erythematous patches to plaque and nodules. Beyond the classical form of MF, other variants have been identified including poikilodermatous MF, pagetoid reticulosis, granulomatous slack skin, folliculotropic MF, and hypopigmented/hyperpigmented MF. Given these protean clinical manifestations, the diagnosis of MF could be challenging and, in the latest years, some dermoscopic tips have been provided in particular for early-stage MF and some variants of MF, as reported below. 


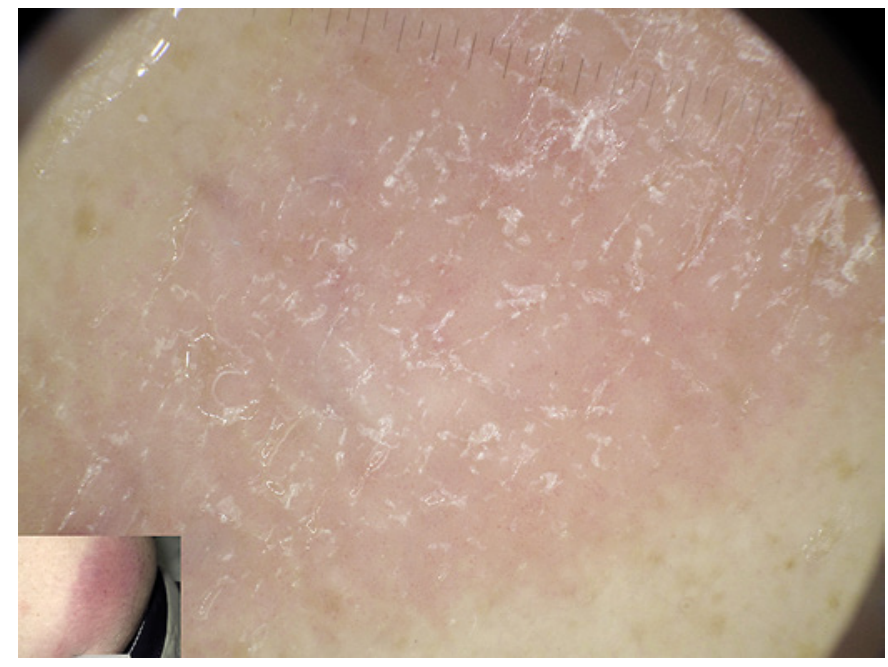

Fig. 1. Fine short linear vessels are one of the most constant features of early MF.

\section{Early-Stage MF}

Lallas et al. [3] analyzed retrospectively a total of 67 dermoscopic images of early-stage MF and found a characteristic dermoscopic pattern consisting of fine short linear vessels (sensitivity $93.7 \%$, specificity $97.1 \%$ ) associated with orange-yellowish patchy areas (sensitivity $90.6 \%$, specificity $99.7 \%$ ). The authors found a characteristic arrangement of linear vessels, named spermatozoa-like, to be highly specific of MF. Conversely, Bosseila et al. [4], by evaluating the angiogenesis in early-stage MF, found the dotted vessels to be the most frequently detectable vascular pattern in $\mathrm{MF}$ at dermoscopy (Fig. 1, 2).

\section{Poikilodermatous MF}

Recently Xu and Tan [5] have described dermoscopy of this unusual variant of MF, revealing as key dermoscopic features multiple polygonal structures consisting of lobules of white storiform streaks characterized by dotted and hairpin vessels, with septa of pigmented dots. In addition, red and yellowish smudges are detectable in poikilodermatous MF.

\section{Pagetoid Reticulosis}

An anecdotal report has shown that dermoscopy of pagetoid reticulosis of the Woringer-Kolopp type reveals a Bowen-like appearance, namely a discrete homogeneous pink background erythema associated with dotted/ glomerular vessels and white scales [6].

Dermoscopy of Cutaneous Lymphoma

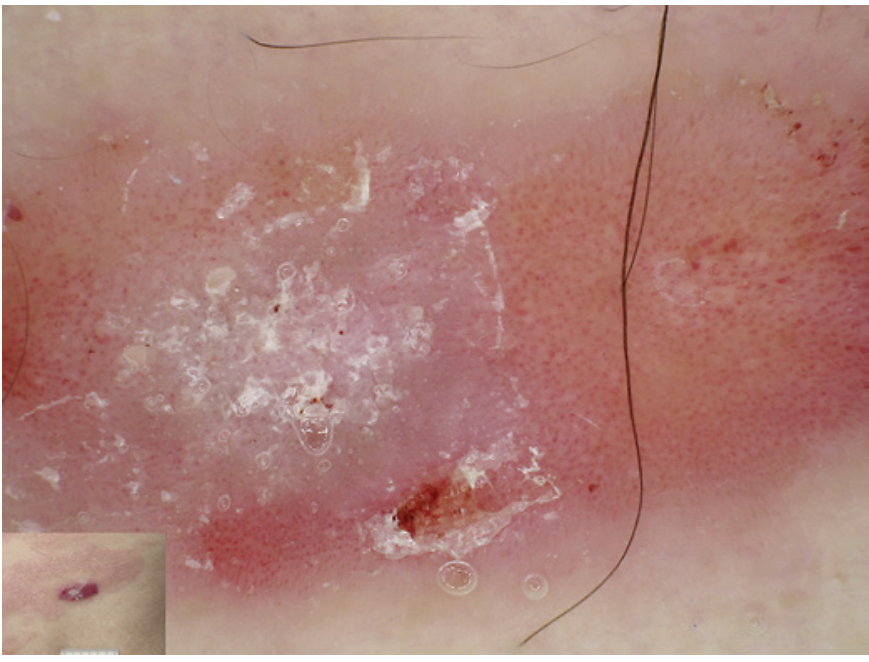

Fig. 2. Orange-yellowish patchy areas associated with linear and polymorphous vessels in a patient with long-standing MF.

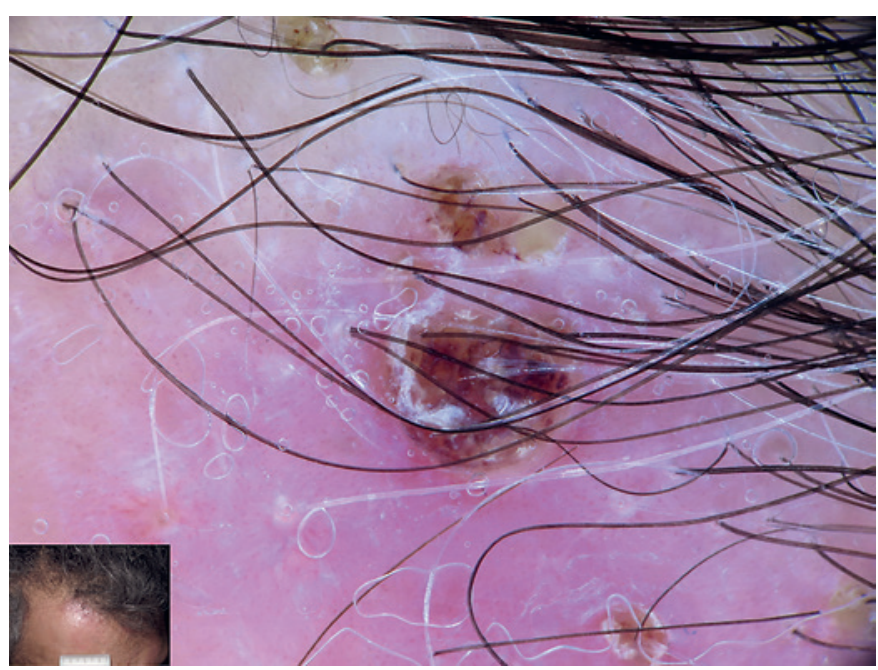

Fig. 3. Follicular crusting and pustules, terminal hairs, and perifollicular accentuation in a patient with folliculotropic MF.

\section{Folliculotropic MF}

Recently Ghahramani et al. [7] have described dermoscopic features of folliculotropic MF, which seem to show, as expected, comedo openings with perifollicular accentuation, small white structureless areas, and terminal hairs (Fig. 3). 


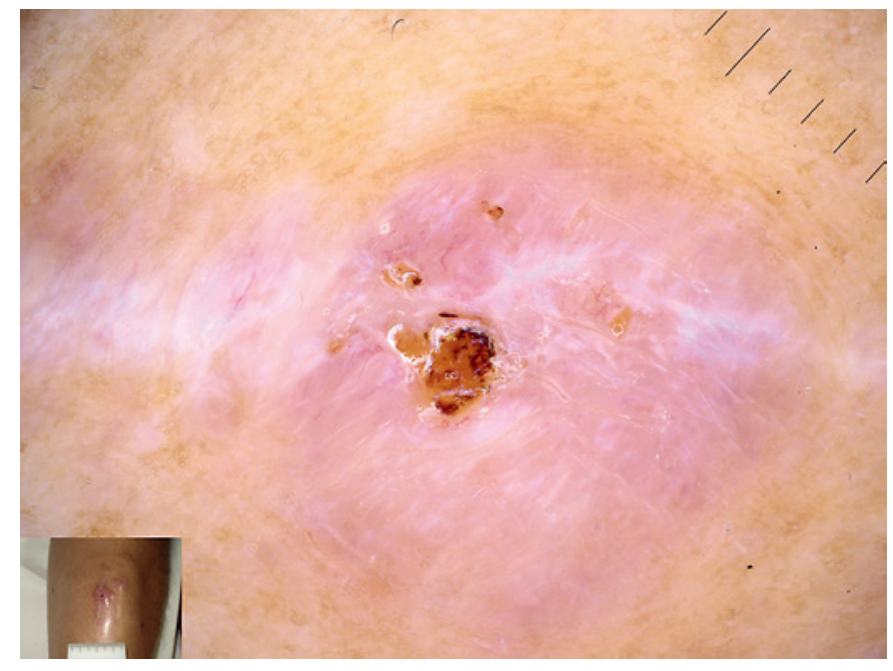

Fig. 4. In this case of recurrent $\mathrm{CD} 30(+)$ anaplastic large cell lymphoma pink-to-yellow structureless areas, polymorphous vessels, and ulceration are detectable.

\section{Primary Cutaneous CD30(+) Anaplastic Large Cell Lymphoma}

The latest revised WHO-EORTC classification includes under the spectrum of CD30+ lymphoproliferative diseases of the skin, CD30+ cutaneous anaplastic large cell lymphoma, lymphomatoid papulosis, as well as borderline cases [18].

Primary cutaneous CD30(+) anaplastic large cell lymphoma is a rare variant of CD30(+) cutaneous lymphoma, whose dermoscopic findings have recently been described as pink-to-yellow structureless areas and polymorphous vessels especially visible at the periphery of the nodular lesions [8] (Fig. 4).

\section{Lymphomatoid Papulosis}

Lymphomatoid papulosis is a primary cutaneous CD30+ T-cell lymphoma clinically characterized by recurrent papular, papulonecrotic, and/or nodular lesions mostly located on the trunk and limbs. Lymphomatoid papulosis has usually a benign course, and lesions at different stages of development can be seen in the same patients. As a consequence of polymorphism of cutaneous lesions, dermoscopy varies with the different phases of the disease $[2,14]$. In particular, the initial inflammatory papular lesion shows a vascular pattern of tortuous radially disposed irregular vessels surrounded by a white

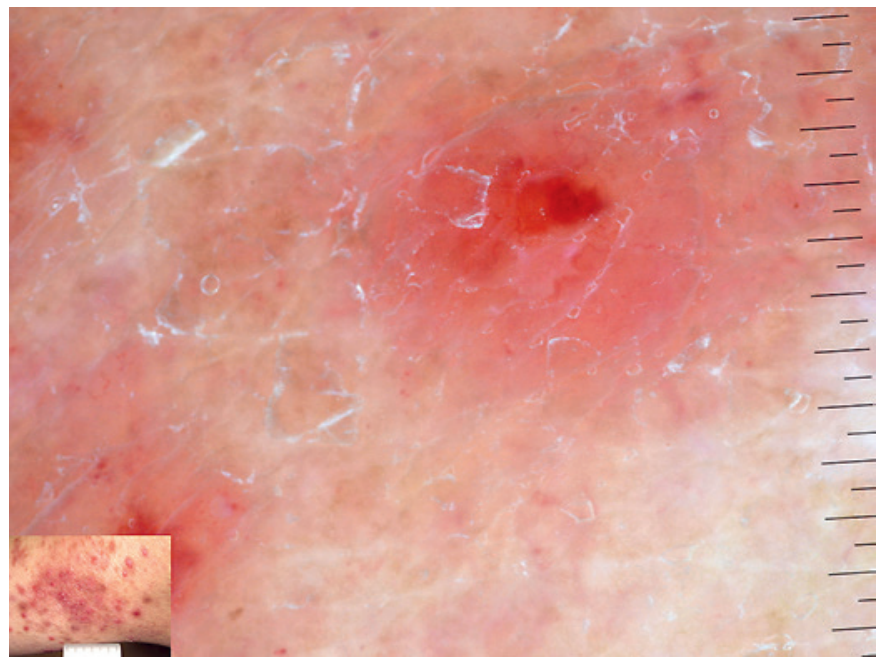

Fig. 5. Necrotic ulcer surrounded by vessels in lymphomatoid papulosis.

structureless area. In the hyperkeratotic papules, the whitish area progressively predominates on the vessels that become less evident. In the last stage, the necrotic ulceration replaces the whitish structureless area, with vessels visible only at the extreme periphery of each lesion (Fig. 5).

\section{Primary Cutaneous B-Cell Lymphoma}

Primary cutaneous B-cell lymphomas (PCBCL) are Bcell lymphomas that originate in the skin and are usually limited to the skin itself at the time of diagnosis. Clinical presentation could be extremely heterogeneous, and histopathological examination plays a key role in the final diagnosis. A retrospective study on 10 cases of PCBCL, presenting clinically as solitary red/pinkish nodules, revealed some interesting data on dermoscopic features of PCBCL [9]. In particular, the most frequent features were white circles with a salmon-colored background/area, scales, and arborizing vessels. The same repetitive features have recently been described in a further 2 cases [10]. Recently, Geller et al. [13] have confirmed these findings except for white circles. To date, no precise correlation exists between each dermoscopic feature and its histopathological correlation. However, the identification of such a combination of dermoscopic features may be very useful in clinical practice for the early recognition of PCBCL and prompt excision of this tumor (Fig. 6, 7). 


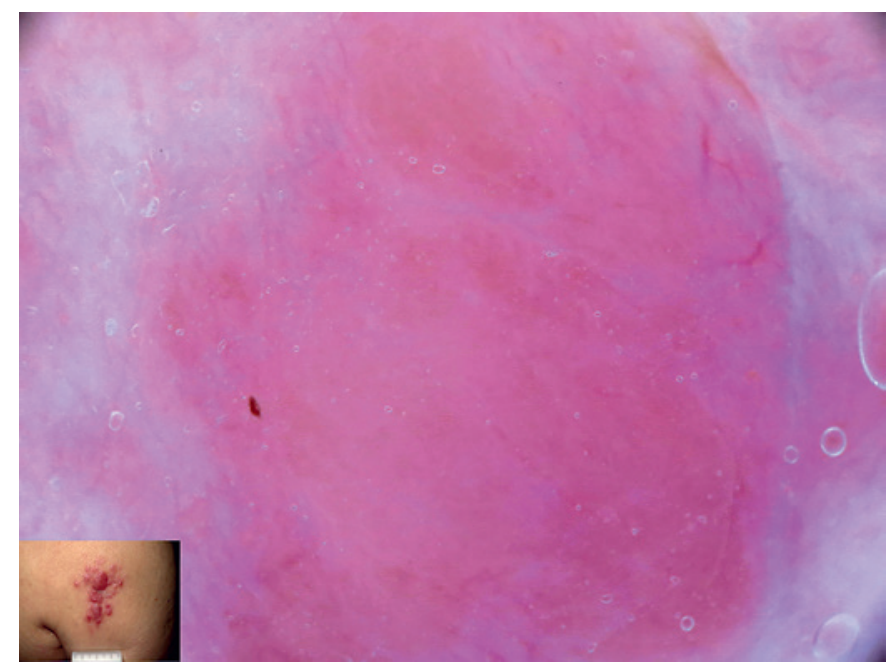

Fig. 6. Dermoscopy of a primary cutaneous follicle-center lymphoma showing salmon-colored background and arborizing vessels at the periphery.

\section{Lymphocytoma Cutis (Pseudolymphoma) and Pseudolymphomatous Folliculitis}

The diagnosis of lymphocytoma could be very challenging, and histopathology is mandatory in most cases. Recently, dermoscopy features have been described, revealing white reticular lines on a pinkish background and some fine linear vessels crossing the white reticular lines [15] (Fig. 8). Pseudolymphomatous folliculitis was first considered as a variant of pseudolymphoma and it is histologically characterized by a dense lymphoid infiltrate associated with hyperplastic hair follicles. In 2012 a dermoscopic description of pseudolymphomatous folliculitis has been published, in particular showing prominent arborizing vessels with small perifollicular and follicular yellowish spots and follicular red dots [16].

\section{Cutaneous Involvement of Multiple Myeloma}

Cutaneous involvement of a hematological neoplasia is a rare occurrence. Clinical presentation could be extremely variable, and no constant features can be identified. Recently, an interesting paper about dermoscopy of skin involvement of multiple myeloma has been published, showing a "pink cobweb"-like appearance, i.e. dilated linear vessels disposed in a rhomboid fashion, mostly evident in new-onset lesions [17].

Dermoscopy of Cutaneous Lymphoma

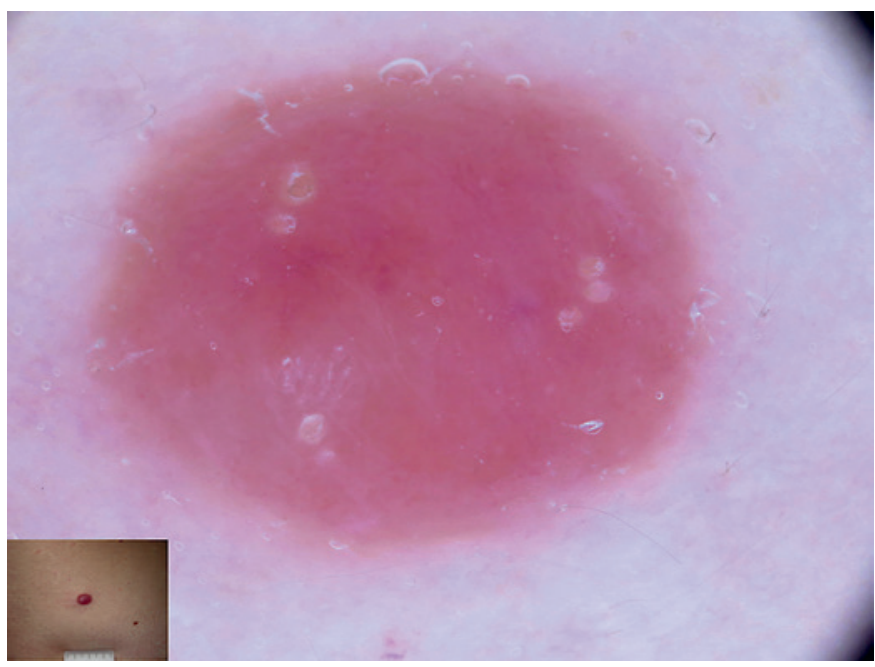

Fig. 7. Primary cutaneous marginal zone lymphoma showing at dermoscopy a salmon-colored background associated with whitish areas/circles.

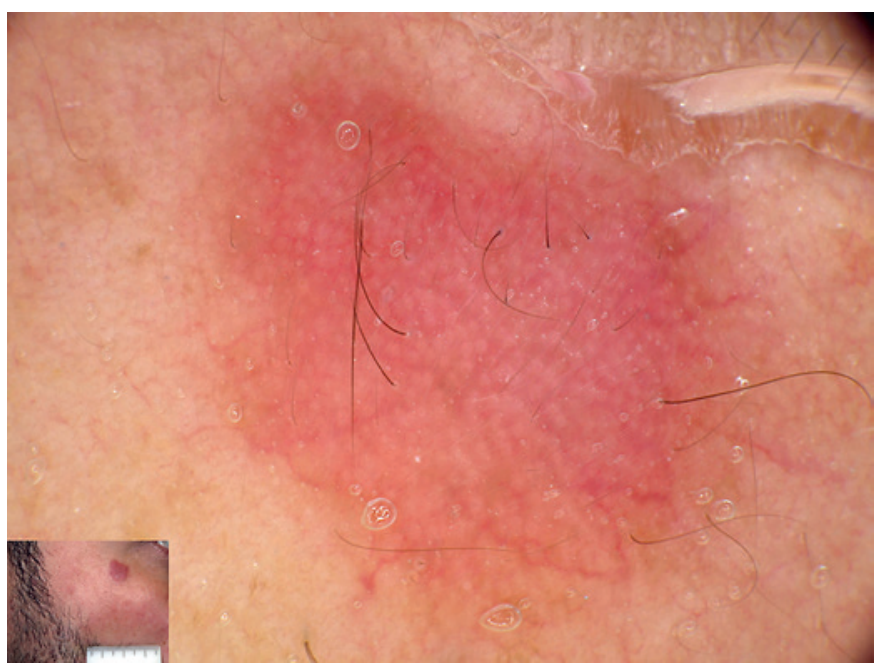

Fig. 8. A case of pseudolymphoma showing at dermoscopy perifollicular vessels and white dots.

\section{Conclusions}

The prompt identification of CLD has always been a challenge in dermatological practice, due to the rarity of this group of diseases, the heterogeneity in clinical presentation, and plenty of variants described in the literature so far. Nowadays, progress in skin imaging, in particular with dermoscopy, has considerably changed the 
diagnostic capability among dermatologists. In the last 5 years, the growing interest toward noninvasive diagnoses of CLD has progressively led to a major confidence with these diseases. It is obvious that histopathology confirmation of the diagnosis is mandatory for CLD, but we can now assert that diagnostic awareness has increased thanks to dermoscopy.

\section{Key Message}

Dermoscopy plays an adjuvant role in the achievement of the diagnosis of cutaneous lymphoproliferative disorders.

\section{Disclosure Statement}

The authors have no conflicts of interest to disclose. There were no funding sources for this work.

\section{References}

1 Cerroni L: Lymphoproliferative lesions of the skin. J Clin Pathol 2006;59:813-826.

2 Moura FN, Thomas L, Balme B, Dalle S: Dermoscopy of lymphomatoid papulosis. Arch Dermatol 2009;145:966-967.

3 Lallas A, Apalla Z, Lefaki I, Tzellos T, Karatolias A, Sotiriou E, Lazaridou E, Ioannides D, Zalaudek I, Argenziano G: Dermoscopy of early stage mycosis fungoides: J Eur Acad Dermatol Venereol 2013;27:617-621.

4 Bosseila M, Sayed Sayed K, El-Din Sayed SS, Abd El Monaem NA: Evaluation of angiogenesis in early mycosis fungoides patients: dermoscopic and immunohistochemical study. Dermatology 2015;231:82-86.

5 Xu P, Tan C: Dermoscopy of poikilodermatous mycosis fungoides (MF). J Am Acad Dermatol 2016;74:e45-e47.

6 Morariu SH, Rotaru M, Vartolomei MD, Turcu M, Chiotoroiu AL, Suciu M, Cotoi OS: Pagetoid reticulosis Woringer-Kolopp type, a particular variant of mycosis fungoides: a case report: Rom J Morphol Embryol 2014;55: 1469-1472.

7 Ghahramani GK, Goetz KE, Liu V: Dermoscopic characterization of cutaneous lymphomas: a pilot survey. Int J Dermatol 2018;57: 339-343.
8 Uzuncakmak TK, Akdeniz N, Karadag AS, Taskin S, Zemheri EI, Argenziano G: Primary cutaneous CD 30 (+) ALK (-) anaplastic large cell lymphoma with dermoscopic findings: a case report. Dermatol Pract Concept 2017;7: 59-61.

9 Mascolo M, Piccolo V, Argenziano G, Costa C, Lo Presti M, De Rosa G, Scalvenzi M, Staibano S: Dermoscopy pattern, histopathology and immunophenotype of primary cutaneous B-cell lymphoma presenting as a solitary skin nodule. Dermatology 2016;232:203207.

10 Piccolo V, Mascolo M, Russo T, Staibano S, Argenziano G: Dermoscopy of primary cutaneous B-cell lymphoma (PCBCL). J Am Acad Dermatol 2016;75:e137-e139.

11 Russo T, Piccolo V, Lallas A, Argenziano G: Recent advances in dermoscopy. F1000Res 2016 Feb 17;5. pii: F1000 Faculty Rev-184. DOI: 10.12688/f1000research.7597.1. eCollection 2016.

12 Russo T, Piccolo V, Lallas A, Giacomel J, Moscarella E, Alfano R, Argenziano G: Dermoscopy of malignant skin tumours: what's new? Dermatology 2017;233:64-73.
13 Geller S, Marghoob AA, Scope A, Braun RP, Myskowski PL: Dermoscopy and the diagnosis of primary cutaneous B-cell lymphoma. J Eur Acad Dermatol Venereol 2018;32:53-56.

14 Caccavale S, Vitiello P, Mascolo M, Ciancia G, Argenziano G: Dermoscopy of different stages of lymphomatoid papulosis. J Eur Acad Dermatol Venereol 2018;32:e198-e200.

15 Namiki T, Miura K, Tokoro S, Tanaka M, Yokozeki H: Dermoscopic features of lymphocytoma cutis: a case report of a representative dermoscopic feature. J Dermatol 2016;43: 1367-1368.

16 Fujimura T, Hidaka T, Hashimoto A, Aiba S: Dermoscopy findings of pseudolymphomatous folliculitis. Case Rep Dermatol 2012;4: 154-157.

17 Dika E, Ravaioli GM, Tacchetti P, Zamagni E, Fanti PA, Ribero S, Misciali C, Patrizi A: Dermoscopy of cutaneous involvement by multiple myeloma. J Am Acad Dermatol 2017; 76:S71-S72.

18 Querfeld C, Kuzel TM, Guitart J, Rosen ST: Primary cutaneous CD30+ lymphoproliferative disorders: new insights into biology and therapy. Oncology (Williston Park) 2007;21: 689-696. 